\title{
Commentary: The Strength of Perceptions in the Dialogue between Asia and Europe
}

\author{
Dominique Girard \\ New Zealand-France Friendship Fund \\ c/ Ministry of Foreign Affairs and Trade \\ Private Bag 18-901, \\ Wellington 6160, New Zealand \\ E-mail:dom678285@gmail.com
}

Since I was kindly invited to contribute a commentary on this publication, perhaps because of my long familiarity with Asia, and certainly because I was the Asia Europe Foundation's Executive Director between 2008 and 2011, I will provide some purely personal views on 'perceptions' in foreign affairs. I shall first show how the sudden perception of themselves as a forgotten part of the world brought a fifth of the French voters out of the political mainstream in the 2012 presidential election. I shall then make a few remarks about how history has shaped the mutual perception between Europe and Asia as much as it has been shaped by it and give a personal estimate of the most significant elements of today's perceptions between the two regions. Finally, after a brief description of how ASEM and ASEF are interesting, if insufficient, answers to our perception gap, I will explain how Asia and Europe run the risk of being distracted from their healthy attempt at dialogue by resurgent xenophobia and demagoguery. In the concluding section I will explore how perceptions studies are now an available and indispensable instrument, which, nonetheless, needs to be supplemented by the development of a multifaceted dialogue similar to what ASEF has been engaged with over the last 15 years.

It was no surprise that foreign affairs were almost absent from debates and candidates' platforms during the 2012 presidential election campaign in France with two exceptions: Europe and, to a much lesser extent, Afghanistan. But Europe is no longer really 'foreign' politics and Afghanistan is seen more as a place where French soldiers die than as a foreign affairs issue in its own right.

Still, the world was everywhere, if indirectly, in the heated discussions of the campaign. Maybe, for the first time in post-WWII history, French voters realised how much their fate was linked to a global situation over which they had little 
control. Everything from employment, purchasing power, taxes, budget, labour law, education, national cohesion to welfare benefits, suddenly appeared to be at least in part dependent upon non-French factors. Acute observers of their fellow citizens, the two main contenders for the presidency reacted in their own way to this. The conservative Nicolas Sarkozy placed an unexpected emphasis on 'borders' as the ultimate protection he would endeavour to provide for the country. The socialist François Hollande re-ignited the concept of the 'French dream' of a nation keeping at its core the task to fight for equality and justice among citizens and peoples.

This is not to say that the French voters - or politicians - were previously unaware of globalisation and its direct consequences on them. Delocalisation, de-industrialisation, and foreign trade challenges have been part of their lives for the last thirty years, succeeding decades of brilliant post-war reconstruction and liquidation of the old colonial empire. Europe had offered a new paradigm and a strong reinforcement for the French determination to remain a world actor. France had managed to establish its place in the driving seat of European construction with Germany as a partner. Paris had also consistently supported the legitimate ambition of 'emerging' nations or regions to regain their place and role in world affairs: the People's Republic of China recognised by De Gaulle as early as 1964, India and Japan, whose candidacies to the UNSC were strongly encouraged, ASEAN and the rest of Asia, enrolled as partners of Europe in the creation of the new dialogue structure ASEM in 1996, etc.

Like many Europeans, the French had unconsciously become somewhat schizophrenic. They rejoiced in the ideas of global change that they had nurtured, but they realised that the same changes had contributed to a supposed delegitimisation of their values and lifestyles. Reaganomics, Thatcherism and their various clones had inevitably evolved globalisation into a system in which the strong became ever stronger, the rich ever richer, leaving everyone else worse-off, and bitter. For example, when Lakshmi Mittal took control of the steel-making company Arcelor in 2006, he displayed remarkable clout and was lauded by many. When he closed furnaces one after the other, confidence vanished among employees and local authorities. Nicolas Sarkozy's failure to keep his promise to ensure the steel mills remained open signalled the beginning of his downhill slide to electoral failure.

In other words, phenomena had occurred in full sight of the public and their leaders, but their perceptions of them had remained superficial or distorted, even in the eyes of the latter. When perceptions became clearer-which does not necessarily mean closer to reality - it was already too late to adjust policies 
or language. Another example can be drawn from recent French politics. The traditional discourse of the far-right Front National had been centered for years on immigration with a more or less overt element of anti-semitism and racism. Against the backdrop of the global financial and economic crisis, this has evolved into a more presentable anti-EU, anti-euro protectionism which could pass for an updated form of tough conservatism were it not for the anti-immigrant and anti-Muslim verbiage. The smart element of this change was the 'protection' jargon, which appealed to a lot of citizens feeling left out and forgotten and who did not understand or accept that their country had to look beyond its own horizons to survive.

Unfortunately, politicians and policy-makers cannot ignore the strength of perceptions when right or left wing extremists take advantage of them come election time. Therefore, 'protectionism' stopped being a dirty word during the campaign, even though it has generally been requalified as 'European'—or 'smart' - protectionism, meaning a more aggressive European stance in WTO discussions on social and environmental norms and reciprocity. A few weeks before the election, the government increased the VAT as a means to favour French-made products and fight delocalisations. Last year, one of the rising stars of the Socialist Party published a book he simply titled De-globalisation. It is unclear whether all this will inspire a significant change in France's position on these issues within the EU, but the interpretation of the public's perceptions has brought about a debate that will not be ignored in the future.

"Congratulations, but you must be aware that when you want to talk to me about Asia, I will always have something more urgent on my agenda". That is how I was greeted by my Foreign Minister when I became head of the AsiaOceania department of the Quai d'Orsay in early 2000. He later changed his mind and became a devoted advocate of French policies in Asia. But I was not that surprised when he offered me his bitter-sweet welcome. I discovered Asia in the mid-1960s, when it was daily in the headlines of the Western media, but mostly because of the nefarious consequences of its miseries: the Vietnam War, the Cultural Revolution, Indonesia's 1965 massacres, the Indo-Pakistani wars, Philippines' chaos, Laos, Cambodia, hunger, poverty, dictatorship, puppet regimes.

Because of its colonial past my country was involved in the region in many ways, which gave it both the experience and the ability to talk to many parties. Later, France jumped on board when 'tigers' and 'dragons' started appearing as the first local pieces of the globalisation puzzle. When I became ambassador to Indonesia in 1992, Jakarta was the second largest recipient of French 
development assistance after Algeria. But there were "more urgent things on the agenda"-Africa, the Middle East, East-West relations, and, of course, Europe. I remember a dinner at the Elysée Palace, where Mitterrand and Soeharto were looking at each other with fascination and an absolute lack of understanding in equal measures. Jacques Chirac, Mitterrand's successor as president, was a precious exception in French politics as he had been a lover and a student of Asian cultures since his youth, a fact he concealed until his accession to the presidency. It would not have been that profitable on the political stage to be known as an informed admirer of Japan, China, India or Mongolia. But it played a big role in Chirac's enthusiastic contribution to the creation of ASEM.

Misinformed 'perceptions' have forever been the major impediment to different world regions and/or nations to engaging in non-confrontational forms of relations. If democratic countries have never been at war with each other, it is probably in part because their citizens' ability to get a relatively accurate image of their neighbours has prevented leaders from using reigning prejudices to support their ambitions. By contrast, lack of knowledge and cultural or religious representations of the Other make it easier for demagogues to enlist the fear of foreigners, or precipitate the idea of the inferiority or dangerous nature of foreign peoples to increase their own following. Incidentally, this phenomenon is not unique to foreign affairs: solid perceptions of internal security problems are powerful instruments used to control the less educated, much more than actual insecurity is. Intercommunal tensions in India, politicisation of Islam in Europe, finger pointing at the Roma immigrants in 2010 France, to name just a few issues, have been, and in some cases continue to be, used in the same spirit.

The last two or three centuries seem to demonstrate that mistaken or partially incorrect perceptions do not prevent countries from dominating others. British strategy in India compensated for the lack of understanding of the sensitivities of the local populations as was shown in the 1857 Mutiny. Military dominance, economic power, and administrative control allowed colonial powers to rule countries they did not care to really understand, in spite of the many signals sent to their occupiers through rebellions, cultural resistance or political agitation. In French Indochina, the police knew of the activities of the nationalists and communists. But the blindness of the politicians and the colonists' greed prevented any new approach to the people's aspirations. Their only possible outlet then became insurgency. Typically, there was a big divide between those who could forge their own understanding of the Other beyond official or dominant prejudice, and their political masters who blindly towed the political line. Self-delusion, obstinacy and aggressiveness are the usual by-products of a refusal to take into consideration what others think of you and of their 
relationship with you. The nineteenth century and most of the twentieth were typified by this lack of understanding, with confrontation and ultimately war the usual consequence.

The Asia-Europe relationship began with huge misunderstandings. French scholar Romain Bertrand recounts the absence of a real "encounter" between the the Javanese elites and the early Dutch merchant visitors: the cultural and social gap separating the latter, who appeared rude, brutish and greedy in the eyes of a Banten aristocracy, attached to its own notions of refinement and propriety, was so wide that what Bertrand calls 'incommensurability' prevented any genuine contact. The same gulf between peoples apparently did not occur in such a shocking way between the Javanese and merchants coming from as far as Persia, Arabia, India or China to trade throughout the archipelago.

Europe's 'discovery' of Asia was unilaterally perceived by the Europeans in terms of possibilities of developing trade and religious expansion and later colonisation. The Asians, and the Europeans themselves, carried by the wave of the Reconquista and their arrival in America, were equally unable to grasp the ambiguity of their first encounters. Spiritual and material values were so divergent that each side developed a completely different interpretation of these initial interactions.

Nonetheless Europe was always, to some extent, aware of the existence and 'originality' of Asia, but its perception was generally biased, sometimes favourably. The Enlightment philosophers imagined an ideal China in such a convincing way that it inspired the (relatively) egalitarian meritocratic system of recruitment of French bureaucrats, which was supposed to mimick the "literati's" competitive exams. The mercantile European elite accurately imagined an affluent Asia, which they ultimately plundered, under the pretext of assumptions of inherent superiority over the refined countries they destroyed. Inept clichés were born from the superficial presence of colonial forces and exploitation. One of the interesting paradoxes of French history is that the most enlightened proponent of free, secular, compulsory education at the end of the nineteenth century, Jules Ferry, was also a fervent organiser of the colonial empire in Africa and Asia. Imperialism was seen as a means to promote and expand values as much as commercial interests. The same humanists who understood their fellow citizens' plea for greater equality and liberty were unable to understand that colonised peoples held the same aspirations in their own context.

In my eyes, the European perception of Asia today consists of a new mixture of images, partly inherited from the past, partly linked to the re-emergence of 
Asia. Poverty, exoticism, refinement, opacity, beauty, numbers, probably come to the mind of most Europeans. Economic renaissance, business opportunities, low cost, competition, social norms, environmental issues, regional tensions, enduring authoritarianism, human rights, growing cultural creativity would be quoted by the better informed. This represents an ambivalent picture, further complicated by the fact that China is the overwhelming star of the region in terms of representation, with India and Japan in distant supporting roles and with individual countries shining more or less in view of their past connections with the beholder, Vietnam for the French, Indonesia for the Dutch... and Singapore for everyone.

All in all, besides specific cultural interests, Asia features as an important region for Europe in strategic terms, but is not a daily preoccupation, nor is it associated with well-defined issues. The old racist concept of 'yellow peril' is fortunately dead and buried, even though the spectacular rise of China meets with awe and apprehension and is often associated with the negative effects of globalisation. The fact that the European leaders, like their other Western peers, have until now been very cautious in depicting what they see as the problems posed by China's attitude towards world trade probably explains why positive perceptions of the reborn giant still prevail. A toughening of official stands on reciprocity, currency or social norms would perhaps reinforce the perception of China as the Other if not the adversary, rather than a loyal and friendly partner.

Ironically, the old habit of using Asia as a model, or at least as an argument in discussions about Europe continues. For example, reference to India may be used to critique the alleged French tendency to complain about their situation when "India" is full of unrestricted enthusiasm about the future and "the Indians" are ready to seize any opportunity to grow and prosper. The example of Singapore is often cited as the ultimate economic and political reference for development and management, applicable in any context, irrespective of local conditions and traditions.

Justified or not, this touching admiration is not always reciprocated. The colonial and imperialist past of European powers is far from being forgotten, much less forgiven. The climate change debate is a revealing forum: Asian nations are even less prepared to assume the commitments expected from them and argue that the Europeans built their industrial development at the expense of their colonies and therefore have a debt to repay. Another aspect of underlying modern prejudice is the scorn often shown in Asia for the European social model. 'Welfare state' is a derogatory term. The concept evokes wasting resources on people who should be accountable for their fate instead of being helped. This perception, which is 
not unique to Asian observers, is, however, reflective of an innate or deliberate ignorance of another vision of society and another historical experience. It naturally serves the purposes of government and business leaders who are in no hurry to see their workforce engage in the fight for the improved social conditions that have created the present situation in Europe.

Such differences in approach are normal given both geographical distance and cultural diversity. The risk is of course that, in a shrinking world, conflicting prejudices can easily turn into mutual hostility. Envy, bitterness, contempt, resentment are more ominous dangers. The irresponsible nationalistic discourse which has again become fashionable might at any time turn the relatively benign misunderstandings between Asia and Europe into possible scapegoats. That would further complicate the slow and so far beneficial rapprochement between the two regions.

Since the middle of the 1990s the Asia-Europe relationship has followed an interesting course as far as the importance of 'perceptions' is concerned. In 1996, both regions decided to set up an official, if informal, dialogue structure called ASEM. No urgent reason forced them to do so, and ASEM's fairly vague agenda remains until now evidence of the predominantly political and even 'intellectual' motivations of its creators. Despite this low technical productivity, many more members have volunteered to join the club, among them such heavyweights as India and Russia. Tellingly, the only permanent institution born out of ASEM is the Asia Europe Foundation (ASEF), endowed with the task to develop intellectual, cultural and people-to-people exchanges between the two regions.

ASEM and ASEF often face criticism, but they symbolise the realisation, at least by some of the participating governments, that international relations today means more than the management of conflicting interests or an adjustment to new global challenges. Coincidentally or not, the concept has materialised at the same time as the Internet wave, which has suddenly and increasingly given populations an unprecedented ability to know more about the rest of the world than a few tired clichés. With the Internet, informed perceptions ceased to be the preserve of elites. Citizens in growing numbers became free to communicate with people across the border or thousands of miles away. Globalisation gave leaders and business the possibility of rationalising production, trade and finance across the planet. It drastically changed the lives of millions of workers and consumers, while preserving most of the existing political systems - democratic or authoritarian. The Internet has started giving ordinary citizens the capacityand hopefully tomorrow the right - to gain some knowledge of their global 
environment, to forge judgements about it and in some cases to engage in real action.

ASEM and ASEF are intended to bridge the perception gap between Asia and Europe. This gap existed at the level of leadership as much as it did at the peoples' level. Of course, globalisation had forced governments and business to make a minimal effort to 'understand' their counterparts in order to facilitate commercial negociations. 'Experts' were requested to provide keys to a better communication between partners. But contacts remained few and superficial and nothing much evolved in the mutual representations. As we saw, a rather benevolent ignorance and reciprocal indifference characterised the relationship. In this context, it was extremely difficult to imagine how and on which topics the Asians and the Europeans could develop some kind of cooperation. And still, the shrinking of the global stage was clearly imposing on both parties a growing contribution to the new international life.

In ASEM, leaders meet, ministers meet, and officials meet — not to negotiate their bilateral deals, but to discuss issues and design common ideas and initiatives between the two regions. Despite the heterogeneity of the two groups, or even perhaps because of it, dialogue among the individuals, who would otherwise have few chances to get acquainted, is real. ASEF brings together civil society or official representatives from all over Asia and Europe, with a preference for younger people, to discuss topics of common interest or to just learn from each other. The objective is never to have one 'side' convincing the other 'side', even on the touchiest issues, like human rights or the environment. It is rather to really listen to each other and to establish connections that could help reach better understanding and mutual respect. Thousands of participants have acquired a totally new image of the other group in these meetings. They bring their perceptions back home and create anew picture of those 'aliens' they once knew so little about.

ASEF has naturally been an enthusiastic supporter of the NCRE's work on EUAsia perceptions and an important partner in the programme. Each meeting of the ASEF Board of Governors gives evidence of the huge work which remains to be done to further understanding and trust and to legitimise open-ended dialogue. A concept like 'civil society', for example, cannot have the same meaning and the same implications in all the ASEF countries. Diplomats are used to the same words not being understood in the same way by all the parties to a treaty, because it can be the only way to advance a tricky debate. But the same approach should not be used when it comes to studying the ability of Asia and Europe to stimulate and facilitate their dialogue. Perception research 
is therefore an essential element now that Asia and Europe have no choice but to co-operate in the 'real' globalised world and when their leaders are more and more accountable to their public opinions about the concrete consequences of globalisation.

As I stated in the introduction to this paper, people today have become aware of their dependence on external factors to an unprecedented level. Local economies depend on regional and/or global evolutions as the 2008 financial crisis and its ongoing aftermath have shown. By the million, people have lost their jobs, their homes, their social benefits and their faith in the future. Thanks to the new media and the Internet, they can see beyond their own miseries and form their own opinions on the origin of their problems. Even in the most remote parts of huge countries, information is available about the haves and the have-nots, unequality, corruption, pollution, and the more or less violent rebellions against unfair policies or authorities in all parts of the world.

Previously a phenomenon confined to democratic regimes, public opinion is now a political reality everywhere. Some governments may try to suppress it or limit its expression, but they can no longer ignore it and they do adjust their policies to accommodate it. This can be seen as a favourable development, since popular perceptions now have to be taken into account. It is also potentially a means of manipulation when 'public opinion', at home or elsewhere serves as a pretext for specific unpalatable measures. All the same, decision-makers know that the relative transparency of information worldwide ensures that they will be somehow held accountable by their population for their policies, including, to some extent, foreign relations, a domain which had until now been left to leaders' exclusive responsibility.

In this respect, the current crisis in Europe has demonstrated how public perceptions seal the fate of leaders considered incapable of protecting their fellow citizens, or worse, guilty of passing the burden of corrective measures on to citizens. 'Indignated', 'indignados', 'indignés' or just ordinary voters in the ballot booth have expressed in significant numbers their rejection of an economic perspective that they thought ignored their problems and pushed them into a kind of civic no-man's-land within their own societies.

In the EU, a sensitive aspect of this new reality is the emergence of a blatant divide between the so-called Club Med countries and the allegedly 'wise' countries, notably Germany. Berlin, because it seemed to call the shots in Europe and to care first for its own interests, faced a wave of unpopularity that re-ignited old anti-German clichés in Southern Europe. A number of economists 
and politicians focused their criticism on Germany's policies of export-oriented growth at the expense of social solidarity since Chancellor Schröder's Hartz labour laws. In a striking parallel, this echoed and underlined the usual criticism against the other world export titan, China. Europe and Asia, in a sense, found common ground in the minds of experts and, unexpectedly, in the opinions of uninitiated observers, which are ultimately more sensitive.

The re-emergence of nationalism is now seen as a fact in Europe with the far-right parties' breakthrough that has already brought them into coalition governments. They capitalise on the disenfranchisement of voters who cannot find explanations for their feeling of exclusion. Enemies are identified to focus their frustration, for example, on foreigners abroad to whom their jobs are transferred and immigrants at home who take jobs and social benefits, the 'elites', responsible for all of this. There may be elements of truth in such a discourse, but paradoxically, the people most responsive to it are not those who are actually disadvantaged by the reality of a globalised world where borders have lost their importance. Rather, they are individuals who are motivated by the fear of losing the little they have accumulated. Once again, perceptions are more important than facts. The tragedy is naturally that the new nationalist parties have nothing to propose but the recipes that brought the planet to war in the 1930s: isolationism, protectionism, xenophobia and racism. Emotions born from strong but misplaced perceptions are doomed to prepare for more disasters.

The first of those is the temptation among democratic leaders to try and retain voters lured by the fatal attraction of extremism by pandering in part to their demands. The problem with this approach is that it generally only gives respectability and legitimacy to attitudes and propositions which are in total contradiction with the principles at stake, and wholly at odds with the lessons of history.

Experts are now well equipped to measure and evaluate perceptions, provided the 'target' is correctly designated and a multiplicity of angles are explored. Diplomats have forever been in charge of the study of local popular opinions both about their home and their host countries. There may be embarrassing exceptions to this rule, but, as the Wikileaks revelations have shown, modern diplomacy pays as much attention to perceptions as it does to the governments and the elites it rubs shoulders with on a daily basis. However, academia can provide a set of more objective instruments to refine the research and the analysis, while avoiding focusing on elements supposed to reinforce any particular policyoriented interpretation of data. The NCRE's work is in this regard an extremely good and innovative initiative and ASEF's governors warmly supported it, both 
when it concentrated on how the Asians perceive the European Union, and when the 'mirror' study—how Europeans perceive Asia—was initiated.

How can interested parties react to this study and to other ones which will hopefully be carried out in the future on the same or bigger scale? As I have tried to explain here, the problem is as much how people in charge utilise the information they are provided with as it is the availability of the information. Rigorous use of fresh and detailed knowledge of mutual or unilateral perceptions provides the first line of defense in keeping international relations free of unfounded clichés, dangerous prejudices and recriminations. In foreign affairs, assuming the challenge of leadership starts with confronting popular opinion, part of this is a corresponding responsibility to educate and inform the masses. Today, in my view, European leaders at home, and also together with their Asian counterparts, should do their utmost to prevent the ominous resumption of xenophobic perceptions. These perceptions have already been sweeping across Europe, but it would be even worse if they were allowed to extend to the rest of the world, and, in particular, if they put at risk the productive relationship which has gradually been taking root between Asia and Europe. As is always the case, this will only succeed on the basis of reciprocity and negotiation. Laying all the blame for the present miseries on unfair competition from emerging economies would be as bad as pouring contempt on countries seen as welfare-obsessed obsolete spendthrifts. Those perceptions should not however be ignored; they should be used to disaggregate international issues constructively.

Perceptions studies should also consolidate attempts to establish better direct communications between peoples and, notably, civil societies. It is an aberration that in the information age so little actually remains known from one region to the other. The dominant feature is ignorance, indifference, and/or confusion and simplification among the majority of the public questioned. Universally, the opinion leaders care for the other region while they are directly involved in an event, a business deal, a visit and generally not more and not longer than that. The media use their extremely atrophied network of correspondents to focus on global rather than local issues or events, and journalists struggle to convince editors to publish or broadcast non-anecdotal or non-sensational reports. Finally, individuals polled confess very little knowledge of the other regions and typically concentrate on the largest countries, except when they have grown an interest through personal contacts or discovery.

The current level of perceptions of other regions is not insignificant, but it is still dismal in view of the short- and long-term challenges involved. It resembles a forced marriage, where the couple hardly meet even on the wedding day. Efforts 
to multiply direct links between individuals, institutions, media, NGOs, cultural networks, research institutes, economic groupings, young and middle-aged politicians, must be developed to an unprecedented level, irrespective of official political agendas. This is the only way to generate knowledge, understanding, and permanent connections on a significant and productive scale. The ASEF experience shows that it is possible and worthwhile, but it clearly must be executed in a much more determined fashion to reach the necessary critical mass. It must also resist any temptation to reduce it to an insipid club banning from its agenda any sensitive issues: perceptions between Asia and Europe will improve through dialogue, and dialogue will improve if it extends to those same challenging topics which serve as the basis for misunderstandings, mistrust and enmity.

Mr. Dominique Girard served as the Ambassador of France to Indonesia (1992-1995), Australia (1995-2000) and India (2002-2007). He is the former Executive Director of the Asia-Europe Foundation, and currently holds the post of co-Chairman of New ZealandFrance Friendship Fund. 